11.

Enseñanza del Derecho 



\title{
EL CURRÍCULO CHILENO DE ESTUdios JURÍDicos
}

["The Chilean Curriculum of Legal Studies"]

\author{
ENZO SOLARI* \\ Pontificia Universidad Católica de Valparaíso
}

\begin{abstract}
RESUMEN
Comparado con otros modelos curriculares de enseñanza del Derecho, el plan de estudios usual en el modelo chileno es temporalmente extenso y dogmáticamente muy exhaustivo, lo que parece requerir de una esencialización que lo abrevie (en ambos sentidos) y que además lo radique en unos necesarios estudios humanísticos previos.
\end{abstract}

\section{Palabras clave}

Currículo jurídico - Enseñanza del Derecho-Humanidades.

\section{ABSTRACT}

In the Chilean model, the current legal education curriculum is quite long and comprehensive, from a dogmatic point of view, compared to other law education models, which seems to require an essentialization to shorten it (both ways) and that it also grounds it in certain necessary previous humanistic studies.

\section{KEYWORDS}

Legal education curriculum - Law teaching-Humanities.

RECIBIDo el 26 de mayo y APROBADo el 8 de octubre de 2012.

* El autor agradece los comentarios y sugerencias que los profesores Gonzalo Gutiérrez, Manuel Carrasco y Christian Viera hicieran a versiones anteriores de este trabajo. 
1. ¿Podrá dudarse de que hay un canon histórico de los estudios jurídicos en Chile? Si se examinan bien las cosas, resulta claro que los estudios chilenos de Derecho tienen casi sin excepción un carácter enciclopedista. El "generalismo" del currículo jurídico ya asomaba cuando no había programas de magíster y doctorado, y ha persistido en estos últimos años al hilo de la consolidación de algunos posgrados. Desde hace mucho tiempo, así, parece perfectamente natural en Chile que la licenciatura en Derecho precise de cinco años de cursos y seminarios universitarios, más una memoria o tesis de grado y un extenso examen de contenidos usualmente oral. Durante esos cinco años, y tanto antes como después de recientes procesos de semestralización, se estudian algunos saberes jurídicos (Derecho romano y sociología del Derecho a veces, casi siempre Teoría, Historia y Filosofía del Derecho), pero además, y con acusada exhaustividad, prácticamente todas las disciplinas dogmáticas existentes en el área del "Civil law": civil, procesal civil, económico, comercial, internacional privado, constitucional, administrativo, internacional público, penal, procesal penal, laboral, tributario, etc. ${ }^{1}$.

2. Sin embargo, esto que es canónico en Chile no lo es en otros lugares. En Alemania, por ej., habiendo también una tendencia hacia la exhaustividad en la formación jurídica (uno diría que el perfil del egresado chileno de una licenciatura en Derecho se aproxima al ideal alemán del "Einheitsjurist"), las cosas tienen otro aspecto ${ }^{2}$. La licenciatura en Derecho tiene ciertos rasgos generales establecidos federalmente, pero su implementación concreta depende sobre todo de cada Estado. Así (induciendo los rasgos comunes sin detenerse en las particularidades que presentan los estudios jurídicos en cada "Land" de la Bundesrepublik), puede decirse que el currículo jurídico

${ }^{1}$ Véase: Guzmán, Alejandro, La enseñanza del Derecho. Historia y perspectivas, en Anales del Instituto de Chile: La educación superior en Chile, 25 (2005-2006) 2, pp. 314-343.

${ }^{2}$ Para lo que sigue, véase ante todo el $\$ 5$ de la Deutsches Richtergesetz. Sigo de cerca, también, la buena síntesis de Llabrés, Antoni, Els estudis de dret en Alemanya, en García Añón, José (editor), Los estudios de Derecho en Europa: Alemania, Francia, Italia, Reino Unido e Irlanda (Valencia, Servei de Publicacions de la Universitat de València, 2008), pp. 33-50 (con abundante bibliografía). Información a partir de muy diferentes puntos de vista es la que ofrece la serie Schriften zur rechtswissenschaftlichen Didaktik, y en la que ya han aparecido tres volúmenes: Brockmann, J. - DiETrich, J.-H. - Pilniok, A., (editores), Exzellente Lehre im juristischen Studium. Auf dem Weg zu einer rechtswissenschaftlichen Fachdidaktik (Berlin, Nomos, 2011), 295 pp.; GRIEBeL, J. - Gröblinghoff, F. (editores), Von der juristischen Lehre. Erfahrungen und Denkanstöße (Berlin, Nomos, 2012), 139 pp.; y Brockmann, J. - Dietrich, J.-H. - Pilniok, A. (editores), Methoden des Lernens in der Rechtswissenschaft. Forschungsorientiert, problembasiert und fallbezogen (Berlin, Nomos, 2012), 298 pp. 
alemán comprende ante todo cuatro años de estudios universitarios, y abarca cursos, seminarios y ejercitaciones en todas las áreas del Derecho: Derecho privado, Derecho público y Derecho penal incluidas sus prolongaciones procesales. Todo comienza con el "Grundstudium", que incluye asignaturas sobre todo obligatorias durante aproximadamente dos años, al término de las cuales hay un examen intermedio solamente universitario (la "Zwischenprüfung"). Luego prosigue con el "Haupt"- y el "Vertiefungsstudium", además de "Schwerpunkte" y "Wiederholungsphase". Entre el quinto y el sexto o séptimo semestre hay aún ramos obligatorios y un itinerario troncal de asignaturas escogidas por el estudiante. En el séptimo u octavo semestre este se prepara (mediante "Examenvorlesungen") para la primera prueba, que es en parte universitaria y en parte estatal. Como se ve, el ejercicio de una profesión jurídica (abogado, juez, notario, fiscal) es en Alemania sumamente exigente. Esa primera prueba ("erste juristische Prüfung") está, en efecto, compuesta de dos exámenes. Uno, el examen universitario de los ramos escogidos por el estudiante y que constituyen una línea troncal de especialización (la "Universitätsprüfung"), y otro, el examen estatal de conocimientos (la "erste Staatsprüfung").

Véase a título ejemplar el plan de estudios de Derecho (hasta la "erste juristische Prüfung") de la Humboldt Universität ${ }^{3}$ :

\begin{tabular}{|c|c|c|c|}
\hline Fachsemester & Studienabschnitte & Module & Studienpunkte \\
\hline \multirow[t]{3}{*}{1.} & \multirow[t]{6}{*}{ Grundstudium } & Zivilrecht I & 19 \\
\hline & & Strafrecht I & 15 \\
\hline & & Öffentliches Recht I & 15 \\
\hline \multirow[t]{3}{*}{2.} & & $\begin{array}{l}\text { Rechtswissenschaftliche } \\
\text { Fallbearbeitung }\end{array}$ & 12 \\
\hline & & Grundlagen des Rechts & 12 \\
\hline & & $\begin{array}{c}\text { BZQ I } \\
\text { (Schlüsselqualifikationen) }\end{array}$ & 10 \\
\hline \multirow[t]{3}{*}{3.} & \multirow[t]{6}{*}{ Hauptstudium } & Zivilrecht II & 13 \\
\hline & & Zivilrecht III & 11 \\
\hline & & Strafrecht II & 12 \\
\hline \multirow[t]{3}{*}{4.} & & Öffentliches Recht II & 15 \\
\hline & & Öffentliches Recht III & 10 \\
\hline & & $\begin{array}{l}\text { BZQ II (fachorientierte } \\
\text { Fremdsprache) }\end{array}$ & 05 \\
\hline 5. & Schwerpunktstudium & Universitärer Schwerpunkt & 32 \\
\hline 6. & & & \\
\hline
\end{tabular}

${ }^{3}$ Disponible en http://www.rewi.hu-berlin.de/sp/2008. Para otro ejemplo de plan de estudios, el de la Universidad de Freiburg i. B., véase: Llabrés, A., cit. (n. 2), pp. 53-58. 


\begin{tabular}{|c|c|c|c|}
\hline 7. & Vertiefungsstudium & $\begin{array}{c}\text { Vertiefung (Repetitorium } \\
\text { und Probeexamen) }\end{array}$ & 44 \\
\hline 8. & & & \\
\hline 9. & $\begin{array}{c}\text { Staatliche } \\
\text { Pflichtfachprüfung }\end{array}$ & BZQ III (Praktikum) & 15 \\
\hline $\begin{array}{c}\text { vorlesungsfreie } \\
\text { Zeiten }\end{array}$ & & $\begin{array}{c}\text { Erste juristische Prüfung } \\
\text { (sog. Referendarexamen) }\end{array}$ & 240 \\
\hline Summe & & \\
\hline
\end{tabular}

Luego de esa primera prueba, es preciso realizar prácticas por un período de dos años (es el "Vorbereitungsdienst" o "Referendariat"), cuyas etapas obligatorias - las "Pflichtstationen-, implican trabajar bajo la tutela de un formador (el "Ausbilder") en un órgano de la jurisdicción civil, en otro de la jurisdicción penal, en otro administrativo y en un despacho de abogados, tres meses como mínimo en cada lugar, más una o más estaciones opcionales (las "Wahlstationen") ${ }^{4}$. Todo lo cual se cierra con un segundo examen estatal (la "zweite juristische Staatsprüfung") -en parte oral, en parte escrito-, que mide la capacidad para desempeñarse adecuadamente en la judicatura, la abogacía o los niveles superiores de la administración, y solo aprobado el cual (cosa que no todos logran, como tampoco todos lo consiguen siquiera en la primera prueba) ya se puede hablar de un abogado en el pleno sentido de la palabra (un "Volljurist").

Así, se ha podido decir que la formación jurídica alemana propende, por una parte, a la "unidad de las profesiones jurídicas: formación unitaria completa para todos los operadores jurídicos (el mismo contenido de los estudios, la misma prueba habilitadora), con una nivelación por arriba. Cualquier egresado está en condiciones de ejercer como un juez y, por tanto, de ejercer cualquiera actividad jurídica (aunque, en la práctica, no más de un $4 \%$ se dedicará a la judicatura -y a la fiscalía-, y un $75 \%$ se dedicará al libre ejercicio de la profesión)", y por la otra, a la "intercambiabilidad de las profesiones ejercidas: esta formación unitaria propicia una gran permeabilidad en el mundo del Derecho entre unas y otras ocupaciones, es decir, el paso de una profesión a otra se da en un grado mucho más elevado que en otros países"

El año 2005 se tramaron acuerdos y declaraciones que mostraron a políticos y académicos alemanes rechazando frontalmente adaptar la tradicional y generalista formación jurídica a los parámetros boloñeses -y sus ciclos de

\footnotetext{
${ }^{4}$ Para las actividades lectivas durante la "Vorbereitungsdienst", véase el ejemplo del "Land” de Baden-Württemberg en Llabrés, A., cit. (n. 2), pp. 59-60.

${ }^{5}$ Llabrés, A., cit. (n. 2), p. 35.
} 
grado o "bachelor" y de "master". A partir de entonces, empero, se ha ido debilitando este casi total rechazo. Hoy la oposición a las adaptaciones aún es importante, pero parece concentrarse en la mayor parte de los académicos y los estudiantes alemanes de Derecho ${ }^{6}$. De todos modos, el "Beschluss" del "Deutsche Juristen-Fakultätentag" correspondiente al 2011 no ha modificado nada de importancia: fuera de algunas alertas y discrepancias, recomienda en general seguir desarrollando y mejorando la formación jurídica alemana ${ }^{7}$. Por otra parte, se aprecia también en el ámbito alemán un creciente desarrollo de programas de licenciatura y "master" en los que se combina el Derecho con la Economía o los negocios (como en la oferta de la conocida "Bucerius Law School"/ "Hochschule für Rechtswissenschaft").

3. España -a diferencia de Alemania- es un país que ha ido adaptándose con cierta docilidad a las directivas boloñesas de convergencia - muy marcadas por ligar los estudios universitarios con la entrada del futuro profesional en el mercado de trabajo y, por ende, con la renta y el crecimiento económico. ¿Qué declaran las universidades españolas respecto de los objetivos que se proponen conseguir impartiendo un grado en Derecho, y de las capacidades que correspondientemente adquirirá el estudiante del mismo grado (el que está sustituyendo a la tradicional licenciatura en Derecho)? Para ello conviene echar un vistazo al currículo del grado en Derecho de universidades españolas prestigiosas como son, por ejemplo, la Autónoma de Madrid y la Pompeu Fabra de Barcelona. La Universidad Autónoma de Madrid, según su propia web, dice que: "el estudiante del grado en Derecho conocerá los fundamentos de los sistemas jurídicos occidentales hasta la actualidad y de ciertas materias no jurídicas, como la Economía o la Ciencia política. Desde una formación interdisciplinar comprenderá el papel del Derecho como regulador de las relaciones sociales, será capaz de interpretar las normas jurídicas, conocerá las instituciones nacionales e internacionales más importantes (ONU, UE, OMC, TEDH...), podrá resolver casos prácticos y exponer de forma ordenada y comprensible argumentaciones jurídicas. Aprenderá también a redactar documentos jurídicos, lo que le facilitará, sin duda, su incorporación al mercado de trabajo"'.

La Universidad Pompeu Fabra, a su vez, declara que: "estos estudios pro-

${ }^{6}$ Para el debate reciente en Alemania en torno al plan de Bolonia y el Derecho, un buen resumen es el de Rodríguez-Rosado, Bruno, La adaptación a Bolonia de los Estudios jurídicos: autocomplacencia inglesa, resistencia alemana, en Revista Jurídica de Investigación e Innovación Educativa, 3 (2011), pp. 61-65.

${ }^{7}$ Disponible en http://www.djft.de/pdf/DJFT_2011_I_End.pdf.

${ }^{8}$ Véase: http://www.law-school.de/.

${ }^{9}$ Véase el folleto informativo del grado en Derecho de la Universidad Autónoma 
porcionan una formación que permite entender la estructura y las funciones de los ordenamientos jurídicos y de sus normas, asimilar los contenidos normativos básicos del Derecho, y saber aplicar las técnicas de argumentación y de interpretación de las normas jurídicas. Esta formación jurídica se complementa con una introducción a los conocimientos de otras ciencias sociales (Economía, Estadística, Ciencia política). El objetivo final es que se tome conciencia del Derecho como un sistema regulador de las relaciones sociales arraigado en los principios constitucionales y, cuando corresponda, en el ejercicio de la autonomía privada. Aquí se combinan dos modalidades de docencia: la magistral y la práctica. Las clases magistrales tienen como objetivo la transmisión crítica de conocimientos y la fijación de los conceptos básicos, partiendo de la lectura previa de materiales. Las clases prácticas promueven la participación activa del estudiante, la capacidad para resolver problemas y para ejercer sus habilidades"10.

En cualquier caso y retórica aparte, es necesario revisar cómo es que se intenta concretar curricularmente estas intenciones. En la Universidad Autónoma madrileña son cuatro los años de estudio para obtener el grado en Derecho (incluyendo un total de 240 créditos) ${ }^{11}$, distribuidos entre la formación básica (60 créditos), los ramos obligatorios (135), las asignaturas optativas (30), las prácticas externas en oficinas judiciales y administraciones públicas ( 6 créditos, tanto las del final del cuarto año como las de las asignaturas optativas según el itinerario escogido) y el trabajo de fin de grado $(9)^{12}$. En la Universidad Pompeu Fabra barcelonesa también son cuatro años los necesarios para la obtención del grado (y también 240 créditos), distribuidos entre asignaturas básicas ( 60 créditos), obligatorias (140), optativas (34, que incluyen 8 créditos por el "practicum" profesional) y el trabajo de fin de grado $(6)^{13}$.

En cuanto a las asignaturas del currículo, he aquí un panorama. En la Universidad Autónoma de Madrid, asignaturas básicas de un semestre de duración son, entre otras: Teoría del Derecho, Derecho romano, Historia del Derecho, Derecho constitucional, Derechos fundamentales, Argu-

de Madrid en: http://www.uam.es/ss/Satellite/Derecho/es/1242658864449/contenidoFinal/Plan_de_estudios.htm?idenlace $=1242661022251$.

${ }^{10}$ Véase: los objetivos del grado en Derecho en: http://www.upf.edu/estudiants/ titulacions/grau-dret/presentacio/index.html.

${ }^{11}$ Se utiliza aquí el sistema europeo de créditos transferibles, conforme al cual cada crédito equivale a 25-30 horas de aprendizaje.

${ }^{12}$ Véase el plan de estudios del grado en Derecho de la Universidad Autónoma en: http://www.uam.es/ss/Satellite/Derecho/es/1242658864449/contenidoFinal/ Plan_de_estudios.htm?idenlace $=1242661022251$.

${ }^{13}$ Véase el plan de estudios del grado en Derecho de la Universidad Pompeu Fabra en: http://www.upf.edu/estudiants/titulacions/grau-dret/pla/. 
mentación jurídica y documentación (todas con 6 créditos). Obligatorias también solo semestrales son, por ejemplo: Derecho constitucional: organización del Estado y sistema de fuentes del Derecho, Derecho procesal: introducción y proceso civil (ambas con 9 créditos), Derecho penal: parte general, Derecho penal: parte especial, Derechos reales, Derecho de familia y sucesiones, Derecho del trabajo, Derecho internacional público, Derecho internacional privado (todas estas con 6 créditos), Derecho procesal: proceso penal, Derecho de la seguridad social y Filosofía del Derecho (con 3 créditos). En la Universidad Pompeu Fabra se ofrece solamente un trimestre de ramos básicos como Teoría del Derecho e Historia del Derecho (ambas con 6 créditos). También simplemente trimestrales son, por ejemplo: los ramos obligatorios de Contratos ( 9 créditos), Derechos y libertades fundamentales ( 6 créditos), Propiedad y Derechos reales ( 5 créditos), Derecho de familia, Derecho Tributario, Derecho procesal civil, Derecho procesal penal y Filosofía del Derecho (todas estas con 4 créditos). Derecho penal es ramo obligatorio y dura tres trimestres: dos dedicados a la parte general ( 5 y 4 créditos respectivamente) y uno a la especial ( 5 créditos). Instituciones de Derecho privado romano es asignatura trimestral que solo aparece en el itinerario de las optativas ( 5 créditos).

El trabajo de fin de grado es en la Universidad Autónoma semestral (9 créditos), mientras que el de la Pompeu Fabra es trimestral ( 6 créditos) y, según la propia web de la universidad, está "orientado a acreditar el suficiente dominio de las competencias y las habilidades del jurista. El trabajo ha de comprender conocimientos de diversas ramas del ordenamiento jurídico e incluir redacción documental y exposición oral. La dirección del trabajo corresponde a un tutor académico que, junto con el estudiante, establecerá la modalidad del trabajo que se ha de presentar (dictamen; preparación y defensa de un caso; preparación de la intervención en un juicio simulado [o "moot court"]; trabajo de investigación de carácter teórico)".

Para entrar en el poder judicial, en fin, o trabajar como fiscal o notario, es necesario hacer oposiciones: exámenes estatales con alto grado de exigencia y competencia. Para ejercer como abogado, solo era necesario hasta el año 2011 ingresar en un colegio de abogados, cosa que cualquier licenciado en Derecho podía hacer. Pero en octubre de 2011 ha entrado en vigor una ley del año $2006^{14}$ que exige a los graduados o licenciados en Derecho, como requisitos previos al ejercicio profesional, cursar un "master" en abogacía y

${ }^{14}$ La Ley N ${ }^{\circ}$ 34/2006: De acceso a las profesiones de abogado y procurador de los tribunales, complementada por el reglamento aprobado por el Real decreto $\mathrm{N}^{\circ} 775 / 2011$. 
solventar un examen estatal. Con ello, el ejercicio de la profesión de abogado en España se homologa a lo que es común en otros países europeos ${ }^{15}$.

4. En EE. UU. el currículo es, desde nuestro punto de vista, peculiarísimo. Allí hay toda una disciplina, la "Legal Education", que ha tematizado esta y otras cosas ${ }^{16}$. Conviene advertir de entrada que lo que se dirá a continuación vale sobre todo para la organización curricular de las facultades de Derecho más prestigiosas y de alcance no solamente estadual sino federal, todas las cuales por cierto están acreditadas por la American Bar Association (ABA) y por la American Association of Law Schools (AALS). Como se sabe, Derecho es en EE. UU. un posgrado para estudiantes con no menos de 22 años de edad -pues ya tienen un "bachelor" en artes o ciencias, o aun en otras disciplinas-, o aún más -ya que muchos han trabajado antes de postular a dichos estudios. Y el bachillerato previo se obtiene en un "college" universitario, donde se sigue una serie de disciplinas tanto humanísticas como científicas -la mitad de las cuales constituye la mención o "concentration" del bachiller, mientras que una cuarta parte de las demás son asignaturas obligatorias básicas, y la cuarta parte restante es un conjunto de ramos por los cuales se ha podido optar con entera libertad.

Es, pues, el Derecho una especialización profesional que -como las de Medicina o Ciencias empresariales- sigue a un bachillerato bastante genérico. Así, la distinción entre pre- y posgrado no tiene mayor sentido cuando se habla de las Escuelas de Derecho norteamericanas. Tales escuelas son escuelas de "graduates", es decir, de estudiantes ya formados universitariamente. Hay que decir, además, que el ingreso en las facultades jurídicas norteamericanas más conocidas (Harvard, Yale, Columbia, Michigan, etc.) es altamente selectivo, y que lo es tanto económica (ya que el costo de los estudios es altísimo) como académicamente (por la suma de exigencias para entrar a estudiar Derecho: no solo el "Law School Admission Test" (LSAT), sino también las notas del "college", además de entrevistas y ensayos).

La carrera de Derecho dura tres años, al término de los cuales se recibe el

${ }^{15}$ Para una mayor información respecto de la enseñanza jurídica española, véase: Peñuelas, Lluís, La docencia y el aprendizaje del Derecho en España. Una perspectiva de Derecho comparado (3a edición, Barcelona, M. Pons, 2009), 104 pp. Y para una interesante presentación de las experiencias de estudiantes de Derecho españoles en las últimas cinco décadas, véase: Atienza, Soledad, The Evolution of Legal Education in Spain, en Journal of Legal Education, 61 (2012) 3, pp. 468-478.

${ }^{16}$ Para consultar multitud de trabajos detallados respecto a la enseñanza y el aprendizaje del Derecho en Estados Unidos es indispensable el Journal of Legal Education de la Association of American Law Schools [disponible en http://www.swlaw.edu/ jleweb/current]. 
grado académico de "Juris Doctor" (J.D.). La licencia profesional se obtiene luego de aprobar el "Bar exam" en el Estado en que se desea ser admitido a la práctica y ser reconocido como "attorney at law". Los abogados norteamericanos no suelen realizar otros estudios de posgrado. Los grados de maestría ("Master of Laws", LL.M.) se obtienen en programas dirigidos a abogados extranjeros (una excepción es la de los LL.Ms. en "tax", que es casi el único caso en el que un abogado estadounidense seguiría estudiando). El posgrado no es, pues, una opción ni siquiera para los que se quieren dedicar a la academia. Los profesores de Derecho no tienen en principio más que un J.D. a su haber. Lo que sí se espera hoy en día -especialmente en las escuelas de mejor "ranking"- es que los postulantes a profesor tengan un posgrado (de preferencia doctorado), pero en otras disciplinas. Así, abundan los profesores con doctorado en Economía, Filosofía, Sicología, Historia, incluso en Ciencias exactas. La realidad del doctorado en Derecho ("Doctor of Juridical Science", S.J.D. o J.S.D.) se parece a la del LL.M.: es sobre todo un programa para abogados extranjeros que quieren dedicarse a la academia en sus países de origen.

En los estudios jurídicos, por otra parte, cosa que aquí solo se puede insinuar, todavía se utiliza profusamente el "case method" elaborado por Ch. Langdell en Harvard hacia 1870 (que de todas formas ha vivido una larga evolución, conocido excepciones y recibido multitud de críticas) con sus corolarios: los "casebooks" (hoy "cases and materials"), los "case briefs" y, por supuesto, el "socratic method"17.

El currículo en una escuela de Derecho es extremadamente flexible. De hecho, lo único permanente y obligatorio es el ciclo de primer año, con sus tradicionales cursos semestrales sobre Contratos, Derecho penal, Proceso civil, Derecho constitucional, "torts" y propiedad, además de algún curso básico de "legal research" o de un "writing program". Últimamente pueden encontrarse también cursos en materia de legislación y regulación, así como en lo que respecta al Derecho comparado e internacional ${ }^{18}$. Se ha resumido felizmente este primer año, poniéndolo en relación con la Historia jurídica

${ }^{17}$ Véase al respecto el ejemplo que pone Gordon, Robert, La educación jurídica en Estados Unidos: orígenes y desarrollo, en Temas de la democracia, 7 (2002) 2, pp. 8-9; y las consideraciones más amplias que ofrecen Toller, Fernando, Orígenes históricos de la educación jurídica con el método del caso, en TENORIO, Guillermo (coordinador), Humanismo jurídico. Ensayos escogidos (México, Porrúa - Universidad Panamericana, 2006), pp. 921-941; y sobre todo PÉrez Lledó, Juan, tanto en La enseñanza del Derecho en los Estados Unidos, en Doxa, 12 (1992), pp. 69-90, como en Teoría y práctica de la enseñanza del Derecho, en Anuario de la Facultad de Derecho de la Universidad Autónoma de Madrid, 6 (2002), pp. 220-239.

${ }^{18}$ Así por ej. en la Harvard Law School (véase: http://www.law.harvard.edu/acade$\mathrm{mics} /$ degrees/jd/index.html). 
norteamericana, tal como sigue: “en el primer año se incluyen, con carácter obligatorio, las 'grandes instituciones' o sectores tradicionales del 'common law', el edificio básico del Derecho correspondiente al liberalismo económico de finales del XIX: 'contratos', 'torts', 'propiedad', 'procedimiento civil' y 'Derecho penal'. Como se ve, se trata básicamente de Derecho privado (con el Derecho penal como 'gendarme'). La fuente casi exclusiva es la jurisprudencia de los tribunales (el 'boom' del Derecho legislado vendrá después), por lo que aquí, el 'case method' campa por sus respetos más que en ninguna otra parte. Y además, enfocado a la manera clásica, como un ejercicio de 'razonamiento jurídico' entendido sobre todo en el sentido de razonamiento 'formal', de sujeción al precedente, de búsqueda de la 'lógica interna' de cada sector de la doctrina que se plasma en una 'línea de casos' bien estructurada (aquí sí hay que memorizar casos emblemáticos y sus principios y doctrinas). Los argumentos de 'policy' juegan un papel mucho menor. Langdell vive" 19 .

De ahí en adelante (en los "upper class courses") casi todo es optativo y depende de lo que los profesores ("faculties") hayan decidido enseñar, pues la gama de tales cursos a elegir varía semestralmente. Pero, claro, tal variación sigue unos programas o líneas de especialización. Se hallan, por ejemplo, en los "upper-level years" programas de estudio en "Law and Government", en "Law and Social Change", en "Law and Business", en "International and Comparative Law", en "Law, Science and Technology", y en "Criminal Justice" 20 . También es tradicional, además de las clases de primer año y los cursos avanzados, que las escuelas ofrezcan seminarios y clínicas. Relacionando de nuevo la oferta académica con el método de enseñanza y la Historia estadounidense, puede decirse entonces en resumidas cuentas lo siguiente: "en el segundo y tercer año todos los cursos son optativos (salvo el relativo a la regulación y Deontología del ejercicio profesional, exigido para tal acreditación). La cantidad y variedad de las ofertas es enorme (no es raro que superen el centenar, aunque la facultad suele proponer 'bloques' con un vago perfil o recomendar encarecidamente algunos cursos). En esta maraña se pueden distinguir no obstante dos grandes 'tipos' de cursos. Estos dos tipos no necesariamente corresponden respectivamente al segundo y tercer año (se trata de 'ganar' un cierto número de 'créditos', distribuyéndose el

${ }^{19}$ Pérez Lledó, J., Enseñanza, cit. (n. 17), p. 90. Para un amplio panorama histórico en torno a la enseñanza estadounidense del Derecho, véase: SHEPPARD, Steve (editor), The History of Legal Education in the United States: Commentaries and Primary Sources (The Lawbook Exchange Ltd., 2007), I-II, 1206 pp. (con diversas perspectivas y remisiones bibliográficas). Un buen resumen al respecto es el de Merico-STEPhens, Ana María, Notas sobre la historia de la enseñanza del Derecho en los Estados Unidos, en Cuadernos del Instituto Antonio de Nebrija, 7 (2004), pp. 157 n. 4.

${ }^{20}$ Extraigo estos programas nuevamente de la página de la Harvard Law School. 
estudiante las materias -salvo algunas 'incompatibilidades' - como prefiera), aunque, dadas las costumbres que los estudiantes siguen al elegir, quizá también se puedan distinguir por años. El primer tipo (o el segundo año de carrera) sería el heredero de la jurisprudencia sociológica y del realismo jurídico, expresaría el programa 'reformista' del 'New Deal', y mostraría la estructura burocrática y la función intervencionista y reguladora del estado del bienestar. Aquí se estudian cursos sobre Derecho tributario, Derecho del trabajo y de la seguridad social, Derecho 'antitrust', Derecho administrativo..., es decir, Derecho público y legislado. También entraría aquí en general el estudio de la reglamentación pública del mundo económico: Derecho de sociedades ('Corporations'), regulación de mercados financieros ('Securities Regulation', 'Acquisitions and Mergers', 'Banking Regulations', 'Corporate Transactions'...), comercio internacional, Derecho concursal, etc. En la docencia de estos cursos entran mucho más que antes las consideraciones de 'policy'. Finalmente, hay un segundo tipo de cursos optativos (a menudo 'seminarios') que lamentablemente se suelen relegar para el tercer año, algo más relajado porque hay que ir ya preparando el 'Bar exam' y entrevistándose para un trabajo. Figuran a veces en el catálogo pensando también en quien quiera continuar con un 'master' o un doctorado. Se trata de cursos sobre materias tales como Historia del Derecho, Filosofía del Derecho, Derecho s humanos, Ciencia política, Teoría social, Derecho comparado, etc. Aquí se ubicarían también las 'nuevas ramas' del Derecho, o el estudio de instituciones más recientes, herederas esta vez de los movimientos sociales de los años '60 (Derecho del medio ambiente, de la salud, del deporte, de los consumidores, 'Public interest Law', asistencia jurídica a los necesitados -'Legal Services'-, Derecho contra la discriminación racial y sexual, Derecho urbanístico, informática jurídica, etc.), así como los cursos de 'Law and ...' ('Law and Society', 'Law and Economics', 'Law and Literature', 'Law and Education', 'Law and Psychology', etc.) y cursos de prácticas como la llamada 'clinical legal education' o la 'alternative dispute resolution' (negociación, mediación, arbitraje). El enfoque de este tipo de estudios está también orientado a la 'policy science', pero esta vez con un bagaje metodológico interdisciplinar mucho mayor, y a menudo se plantean cuestiones valorativas, de índole moral y política, que en los otros cursos apenas se suscitan o no se abordan abiertamente"21.

5. Este brevísimo vistazo comparativo permite tomar alguna distancia para evaluar más reflexivamente si conviene mantener o alterar un canon como el chileno, vale decir, para juzgar si la dimensión normativa envuelta

\footnotetext{
${ }^{21}$ Pérez Lledó, J., Enseñanza, cit. (n. 17), pp. 91-92.
} 
en toda pretensión canónica tiene entre nosotros buen respaldo. Por ello es útil considerar atentamente otros diseños curriculares de los estudios jurídicos, atendiendo tanto a los culturalmente próximos como a otros que, si más lejanos, poseen de todos modos culturas jurídicas dogmáticamente más sofisticadas que la nuestra. Los de Alemania, España y EE. UU. son tres diferentes modelos, uno generalista como el nuestro (el alemán), otro ya menos generalista y que sigue casi al pie de la letra el proceso boloñés (el español actual), y un tercero, el menos generalista de todos, que trata el Derecho como un asunto de posgrado (el estadounidense). En ellos, sobre todo en el estadounidense y el alemán, se ha desarrollado una poderosa reflexión respecto de la organización que en las instituciones universitarias ha tenido y debiese tener tal currículo. La manera estadounidense de disponer, entender e incluso enseñar el estudio del Derecho - con previos estudios universitarios de grado que suelen dar al estudiante una amplia formación humanística y en ciencias formales, naturales y sociales- es la más peculiar de las tres, si se la contempla desde el punto de vista chileno. Alemania y España, por su parte, reflejan hoy por hoy distintas maneras de adaptarse al espacio europeo de educación superior de acuerdo con el proceso de Bolonia: el alemán resistiéndolo y defendiendo sus propias tradiciones de organizar los estudios de Derecho, el español en cambio adoptándolo y haciendo cuantas modificaciones sean necesarias según el espíritu fuertemente británico de dichos lineamientos ${ }^{22}$.

${ }^{22}$ La "Declaración de Bolonia”, de 1999, estableció que el espacio europeo de educación superior constará de dos ciclos principales, el primero con un mínimo de tres años de duración y obligatorio para acceder al siguiente, y cuyo título certifica una cualificación adecuada para el mercado de trabajo, y el otro, el segundo, que ya conduce a un título de maestría o doctorado. El modelo británico de estudios jurídicos, dicho sea de paso, está en el origen de este proceso europeo de convergencia, pues como se sabe contempla dos ciclos, uno de grado o "bachelor" y otro de "master": "el Bachelor of Laws" (LL.B.) tiene normalmente una duración media de tres años, aunque no faltan Universidades, como la de Oxford, que ofrecen la posibilidad de un "bachelor" de cuatro años, incluyendo entonces un año de estancia en otra Universidad europea. El "bachelor" incluye una serie de materias obligatorias, determinadas en todo caso por la Universidad, pero en las que suelen coincidir "Public law", "European law", "Procedural law", "Criminal law", "Trust and Equity", "Law of obligations" y "Property law", y otra lista, generalmente muy amplia, de optativas. En el caso de los estudios de Derecho, no existen "bachelor" de dos años, no previstos en el sistema diseñado por el proceso de Bolonia, que sí existen en cambio en otras áreas de conocimiento. Al acabar el "bachelor" los alumnos tienen la posibilidad de hacer un "master of Laws" (LL.M.), con un contenido mucho más especializado, y cuya duración normalmente es de un año. Pero hay que tener en cuenta que ese "master", al que acuden muchos estudiantes de otros países, no habilita directamente para el ejercicio de las profesiones jurídicas, típicamente la abogacía en sus diversas formas ("solicitor", "barrister"). El ejercicio de esas profesiones, que 
De ahí que uno se pregunte si hay que seguir reconociendo virtualidad normativa a un canon como el chileno. La pregunta supone concebir esta posibilidad: la de desafiar nuestra usual, casi natural, organización de los estudios de Derecho. Cuando menos son dos las cuestiones que merecería la pena discutir: la de la extensión cronológica de los estudios jurídicos, y la del tipo de cursos y seminarios que durante tal período debería desarrollarse. Incluso dejando aparte unos previos estudios de "bachelor", o posteriores de "master" y doctorado, así como las prácticas y exámenes que hemos vislumbrado en aquellos "curricula" jurídicos, los tres suelen incluir muchísimo menos enseñanza dogmática que el chileno, y en todo caso contemplan menos años de estudios universitarios: cuatro España y Alemania, tres los EE. UU. ¿Hay buenas razones para recomendar un acortamiento de nuestros cinco años de estudios, así como para modificar sustancialmente el agregado y la índole de asignaturas que habría que cursar en una licenciatura jurídica?

6. Tal vez convenga detenerse aún en estas tres culturas jurídicas, para entender más cabalmente por qué en ellas se han precipitado semejantes organizaciones curriculares y, a la vez, para plantear más adecuadamente algunas preguntas a nuestra propia cultura jurídica y a su modo acostumbrado de entender los estudios de Derecho. En este sentido, será útil referir una que otra reflexión hecha en esos países con respecto al estatuto intelectual de la profesión de abogado y al consiguiente modo de organizar universitariamente su enseñanza y aprendizaje.

En pleno siglo XIX, en Alemania, parece que ya no era raro ver en el Derecho una rústica profesión. En sus conversaciones con Goethe, Eckermann hace notar que ya en su época estudiar Derecho no constituía una ocupación intelectualmente muy bien considerada sino más bien alimenticia ("ein Brotstudium"): aun estudiando jurisprudencia, dice en la "Einleitung" a su obra, pueden alcanzarse "altos conocimientos de otro tipo" ("höchsten Kenntnissen anderer Art” ${ }^{23}$. Interesantemente, además, en estas mismas conversaciones Goethe alerta contra la tendencia del profesor universitario

en Reino Unido ni siquiera exige de estudios jurídicos universitarios, ya que es posible llegar a ella por vía de unos años de pasantía o ejercicio práctico, o mediante un curso de adaptación para graduados de otras especialidades ("Graduate Diploma in Law"), requiere en todo caso la superación de unos cursos, el "Legal Practice Course", para los "solicitors", y el "Bar Professional Training Course", para los "barrister", supervisados por los respectivos colegios profesionales”: RoDRíGUEZ-RosADO, B., La adaptación a Bolonia, cit. (n. 6) p. 57. Para mayores detalles, véase: PALAO, Guillermo, Los estudios de Derecho en los estados europeos de habla inglesa: Reino Unido e Irlanda, en GARcía AÑón, J., cit. (n. 2), pp. 186-213.

${ }^{23}$ Eckermann, Johann Peter, Gespräche mit Goethe in den letzten Jahren seines Lebens 1823-1832 (Berlin, Aufbau-Verlag, 1956), p. 44. 
a extender la duración de su disciplina más allá de lo que es razonable para sus estudiantes. Partiendo del caso de los que estudian medicina, a quienes se les suele suministrar más química y botánica que la que necesitan para ser competentes en Farmacología, saca esta lapidaria conclusión: "de ello no se obtendrá nada (“daraus aber kann nichts werden”) ${ }^{24}$. ¿No tienen estas dos insinuaciones alguna vigencia incluso hoy? Quizá de manera especial en Chile, ¿no es con frecuencia el abogado, aun estudiando mucha dogmática jurídica (o tal vez precisamente por ello), un profesional poco culto? ¿Y el mismísimo profesor de Derecho alguien que a veces cree que mientras más largamente imparta su propia disciplina, mejor?

Un siglo después, en España, un filósofo parece recoger el guante y querer combatir esta deriva afirmando que la universidad -en la que se realiza la enseñanza del Derecho- ha de cumplir una exigente misión intelectiva. Es, en palabras de Ortega y Gasset, la dimensión esencialmente cultural de la función universitaria. Los fines de las universidades, dice, son el profesionalismo, la investigación y la cultura, vale decir, la formación de profesionales, la preparación de investigadores y, en todo caso, la educación de hombres cultos $^{25}$. Ortega enfatiza especialmente esta función cultural de la que estaría tan carente la universidad contemporánea. La enseñanza y transmisión de la cultura se ha ido perdiendo. Los profesionales e investigadores de hoy adolecen de una grave incultura y barbaridad: "este nuevo bárbaro es principalmente el profesional, más sabio que nunca, pero más inculto también -el ingeniero, el médico, el abogado, el científico" ${ }^{26}$. Es cierto que la sociedad requiere muchos profesionales y algunos investigadores, pero necesita, antes que todo ello, la tradición de las ideas del tiempo que se vive: "la enseñanza superior es primordialmente enseñanza de la cultura o transmisión a la nueva generación del sistema de ideas sobre el mundo y el hombre que llegó a madurez en la anterior" 27 . La pregunta, obviamente pertinente para muchos ambientes universitarios contemporáneos, ¿no lo será de manera especial para los chilenos? ¿O es que nuestras universidades -donde se enseña Derecho- son unas instituciones 'de educación superior' que cumplen satisfactoriamente aquella función cultural? Si es notable el explosivo aumento de la cobertura universitaria y técnico-profesional en Chile (que casi abarca a un millón de estudiantes), ¿no lo es también el discutible nivel intelectual, docente e investigador de tantas universidades, institutos profesionales y centros de formación técnica? ¿Exagera quien dice que campea

${ }^{24}$ Eckermann, J. P., cit. (n. 23), p. 106.

${ }^{25}$ Véase: Ortega y Gasset, José, Misión de la Universidad, en Obras completas 1926-1931 (Madrid, Taurus, 2005), IV, pp. 536-542.

${ }^{26}$ Ibíd., p. 539.

${ }^{27}$ Ibíd., p. 542. 
en las universidades chilenas un profesionalismo tendencialmente bárbaro y mercantilizado? ¿O el que afirma que nuestras universidades son "malas y caras?" 28 .

Esto de la mercantilización y del estrechamiento profesionalizante de las universidades es insoslayable, si bien se presta - hay que reconocerlo- para malentendidos y eslóganes. En EE. UU., país donde el interés crematístico sobrevuela peculiarmente la educación universitaria, hay sin embargo una muy rica tradición pedagógica -Dewey es solo un nombre- para la cual ni siquiera la enseñanza de saberes tan profesionales como los jurídicos es concebible sin una sólida base humanística. Que la universidad deba ser una

${ }^{28}$ Es lo que afirma EDWARDs, Sebastián, Nuestra tragedia universitaria, en La Tercera (7 de enero de 2012), p. R8. De otro de los numerosos análisis acerca de los problemas estructurales -académicos y financieros- del sistema universitario chileno extraigo este botón de muestra: "el sistema universitario chileno es como un reactor fuera de control. Está creciendo, en número de alumnos, a gran velocidad sin que ningún pensamiento estratégico defina su tamaño, su costo y su nivel de calidad real. Existen (en 2011) 630.000 alumnos que se distribuyen en dos sistemas muy diferentes. El sistema nacional universitario (SNU) constituido por una mezcla peculiar de 25 universidades, 16 de ellas estatales y 9 privadas tradicionales. El SNU trata de ejercer sus funciones de docencia, investigación y extensión de acuerdo a parámetros internacionales sobre la naturaleza de la función universitaria (300.000 alumnos, 87\% de la investigación científica, $90 \%$ de la educación de posgrado, proyectos de I+D de importancia estratégica). En paralelo, desde 1981, existe un sistema privado (SPU), esencialmente desregulado, que define sus propias metas de matrículas, sus aranceles y el uso de los excedentes. El SPU funciona con otra envolvente de parámetros. Aunque ya es masivo (300.000 alumnos desde el 2009) no hace casi investigación científica (solo 8\%), no otorga postgrado, no participa de proyectos estratégicos y es poco transparente en el uso de los fondos obtenidos por aranceles y matrículas. Adicionalmente, desde la existencia de los créditos con aval del Estado (desde 2006) se produce el efecto perverso de que las universidades pueden expandir su matrícula de pregrado sin riesgo financiero, y sin tener que preocuparse por la empleabilidad a futuro. En la práctica Chile tiene, en el SPU, un sistema universitario paralelo que obtiene ingresos por más de US\$1000 millones/año, tiene poquísima regulación en cuanto a calidad, no participa del esfuerzo de $\mathrm{I}+\mathrm{D}$ que demanda el país, tiene poco riesgo financiero, y parece no estar consciente de que está saturando el país con profesionales que no tendrán empleabilidad de acuerdo a su entrenamiento. La falta de una política que asegure equidad en el ingreso (y en empleabilidad futura) y calidad está comenzando a incubar una situación socialmente compleja que nos aleja de ser un país desarrollado. Aunque duela decirlo, la proliferación de Universidades (¡60!), programas o carreras (180 solo para estudiar Derecho ) y alumnos (9900 alumnos entraron a Derecho en 2011) nos aleja del objetivo estratégico de ser una 'sociedad del conocimiento'": LeTELIER, Juan Carlos - Mpodozis, Jorge, El sistema es un escándalo y hay que pararlo (2011), en Números, calidad, equidad y diseño en el sistema universitario chileno. Dirección de Innovación y Transferencia Tecnológica. Facultad de Ciencias. Universidad de Chile [disponible en http://www.vamosviendo. cl/textos/universidad.pdf]. 
experiencia cultural de gran envergadura es algo que allí se toma muy en serio. Por esto es por lo que es notable el papel que aún juegan las humanidades en la formación jurídica y, por ende, la función ampliamente cultural que asume la universidad norteamericana en una carrera profesional como la jurídica. Ejemplar es en este sentido lo que dice S. Breyer, juez de la Corte Suprema, en una entrevista cuyo inicio transcribo: "-Comencemos con su época de estudiante. Usted hizo su bachillerato en Stanford University, ¿no es así? -Crecí en San Francisco, fui a Lowell High School, el mismo colegio al que había ido mi padre. Después ingresé a la Universidad de Stanford, a la que también había asistido mi padre, y estudié Filosofía y un poco de Economía. Terminé el bachillerato con mención en Filosofía. En Stanford fui alumno de un filósofo que después llegó a ser muy conocido, Donald Davidson. Luego fui a Oxford, Inglaterra, para continuar mis estudios en Filosofía. Allí seguí el programa de Filosofía, Política y Economía. - En aquel entonces ¿pensaba que se dedicaría después a la Filosofía o tenía en mente el Derecho? -El Derecho. Mi padre era abogado. - ¿Qué recuerdos tiene de Oxford? - ¡Fue maravilloso! ¿Quién no volvería a eso? Siento que aprendí mucho. La gente ahora critica los años cincuenta y los primeros años sesenta durante los cuales yo crecí, pero quienes vivimos esa época la disfrutamos mucho. Oxford tuvo entonces su período de oro. Jeffrey Warneck y Patrick Gardner eran mis mentores, y solía ir a los seminarios de Strawson e incluso de J. L. Austin, gran filósofo, quien todavía estaba vivo durante mi primer año allá, 1959. Y de Economía aprendí mucho con David Worswick. También asistí a las clases de H. L. A. Hart, que después las convirtió en su libro El concepto de Derecho. En esa época ya era bastante claro que Hart iba a ser muy importante, porque la gente encontraba muy interesantes sus planteamientos que trataban de combinar el Derecho y la Filosofía. Después escribió un libro maravilloso, Causation in the Law, junto con Honoré. [...] —Después usted fue a la Universidad de Harvard, ¿qué corrientes predominaban entonces en Harvard? - Entre 1961 y 1964 fui a la Escuela de Derecho de Harvard, porque el Derecho en Estados Unidos es una carrera de posgrado. Harvard estaba muy influido en esa época por las ideas de tres importantes filósofos del Derecho: Henry Hart (ninguna relación con H. L. A. Hart, pero seguramente de igual o mayor importancia para el sistema del Derecho norteamerican), Lon Fuller y Albert Sachs. Este último escribió poco, pero desarrolló muchas ideas de los otros dos y creó una teoría funcional y teleológica del Derecho. Una teoría del Derecho muy poderosa, que antecedió a los Estudios jurídicos críticos y que estructuró sistemas de pensamiento jurídico que permitirían a abogados y jueces trabajar con el Derecho como un instrumento humano (en contraste con lo que ofrece el realismo jurídico, el cual, aunque pienso 
que tiene alguna validez, no nos ayuda mucho a decidir qué forma dar al Derecho ni cómo solucionar los problemas)" 29 .

Semejante papel cultural de los estudios universitarios, aun de los más tecnificados e instrumentales, y sin el cual estos terminan facturando profesionales sumamente ignorantes y poco universales, es lo que impulsa algunas recientes y cerradas defensas de la educación humanística. Luego del famoso alegato de A. Bloom - The Closing of the American Mind-, ha elevado últimamente la voz M. Nussbaum bajo la forma de una franca requisitoria de la educación superior "con fines de lucro, la que, a su modo de ver, es peligrosa para la democracia y sus ciudadanos: "es imposible que las instituciones terciarias y universitarias transmitan el tipo de enseñanza que hace a un ciudadano del mundo si no cuentan con estructuras dedicadas a la educación humanística, es decir, con al menos un conjunto de cursos de formación general para todos los alumnos aparte de las materias obligatorias para cada carrera principal [...]. Hoy seguimos reafirmando que elegimos la democracia y el autogobierno, y suponemos también que nos gusta la libertad de expresión, la comprensión y el respeto por la diferencia. Nos llenamos la boca hablando de estos valores, pero pensamos muy poco en lo que deberíamos hacer para transmitirlos a la próxima generación y así garantizar que sobrevivan. Distraídos por la búsqueda de la riqueza, nos inclinamos cada vez más por esperar de nuestras escuelas que formen personas aptas para generar renta en lugar de ciudadanos reflexivos. Bajo la presión de reducir los gastos, recortamos precisamente esas partes de todo emprendimiento educativo que resultan fundamentales para conservar la salud de nuestra sociedad [...]. Las democracias cuentan con un gran poder de imaginación y raciocinio, pero también son propensas a las falacias, al chovinismo, a la prisa, a la dejadez, el egocentrismo y a la estrechez de espíritu. La educación orientada principalmente a la obtención de renta en el mercado global magnifica estas fallas y produce semejante grado de codicia obtusa y de docilidad capacitada que pone en riesgo la vida misma de la democracia, además de impedir la creación de una cultura mundial digna" 30 .

Un intelectual catalán prosigue -es algo muy reciente- este tipo de apología de las humanidades, si bien con un acento aún más lúgubre. La universidad española -dice,- ha ido adoptando sin reservas casi el proceso de Bolonia, lo que parece conducirla por una pendiente mercantilizadora que sin ningún complejo terminará desplazando de su seno a las humanidades: “[el Plan Bolonia...] tiende a la especialización más indiscriminada, solo

29 "Entrevista a Stephen Breyer, juez de la Corte Suprema de EE. UU." (trad. J. Klein y R. Correa), en Estudios Públicos, 80 (2000), pp. 120-121.

${ }^{30}$ Nussbaum, Martha, Sin fines de lucro. Por qué la democracia necesita de las bumanidades (trad. M. V. Rodil, B. Aires, Katz editores, 2010), pp. 129 y 187-188. 
aspira a una vinculación eficaz, política y económicamente hablando, entre las carreras cursadas y el mercado de trabajo, y subestima tanto la existencia como la función de las facultades humanísticas de todo el continente, en las que desea que se produzca, de un modo u otro, una restitución a los poderes públicos de la inversión realizada en el terreno universitario: la cuestión del saber, en sí mismo -que siempre ha quedado al margen del rendimiento económico, pero que lo ha significado casi todo en el desarrollo de la civilización europea y en la formación del espíritu de su ciudadanía-, quedará marginada y más desprestigiada que nunca en la vida de toda la universidad inmersa en este Plan" 31.

¿No se percibe ya entre nosotros la presión que esas tendencias lucrativas ejercen sobre los estudios superiores -en los jurídicos como en muchos más-y que alarman a universitarios europeos y norteamericanos $?^{32}$.

${ }^{31}$ Llovet, Jordi, Adiós a la universidad. El eclipse de las Humanidades (trad. A. Fuentes, Barcelona, Galaxia Gutenberg - Círculo de Lectores, 2011), p. 199.

${ }^{32}$ Aunque el asunto escapa a los límites de este texto, tiene tal importancia y tantas consecuencias que merece un breve comentario. En efecto, una de las manifestaciones del asalto universitario por parte de criterios lucrativos es la del sometimiento de los proyectos de investigación en el ámbito de las humanidades (iy del Derecho!), así como de las consiguientes publicaciones en revistas periódicas especializadas, a unas evaluaciones reducidas a ciertos mecanizados indicadores de impacto. Esto es algo, como se ha advertido, potencialmente ruinoso, en la medida en que incentiva económica y académicamente un aumento (y si exponencial, miel sobre hojuelas) de la productividad medible en términos del número de artículos (más incluso que de libros y traducciones) colocados en revistas bien listadas internacionalmente (bajo el lema "publish or perish"). Llovet lo ha denunciado en el caso de la universidad española: "a consecuencia de este sistema de evaluación, los profesores se han obsesionado en generar la mayor cantidad de artículos y de libros posible, siempre en el bien entendido de que es suficiente mencionar los títulos de estas publicaciones y nada más [...] En el mejor de los casos, nuestros profesores conseguirán, con publicaciones a menudo desdeñables y faltas de método, interés y ciencia, alcanzar una cátedra universitaria. Pero para entonces ya serán - por no haberse percatado de que se encuentran atrapados en una jaula sin salida- la encarnación del perfecto negativo de lo que debe ser un intelectual": LLOVET, J., cit. (n. 31), pp. 172 y 180. Llovet recomienda en este sentido el libro de WATERS, Lindsay, Enemies of Promise: Publishing, Perishing, and the Eclipse of Scholarship (Chicago, Prockliy Paradigm, 2004); véase: Llovet, J., cit. (n. 31), pp. 175-178. Mientras que Nussbaum hace lo propio -a propósito de las universidades británicas- con el artículo de Collini, Stefan, Impact on Humanities: Researchers Must Take a Stand Now or Be Judged and Rewarded as Salesmen, en Times Literary Supplement, 13/11/2009, pp. 18-19: “[...] el organismo responsable por la educación superior en Gran Bretaña hoy forma parte del Departamento de Comercio. A Collini le parece preocupante que nadie proteste contra la degradación del vocabulario usado, que representa la investigación como una suerte de actividad para la venta ambulante. Según el historiador, 'tal vez nuestros oídos ya no escuchan [...] lo absurdo que es proponer que la calidad de un 
7. Pues bien, a la luz de lo anterior hay que volver a las cuestiones con las que comenzaba este texto. Estas pueden encararse ahora con mayor conocimiento de causa y sin rodeos: ¿habrá una buena razón para que lo que toma tres o cuatro años en muy buenas universidades extranjeras tenga que tomar cinco años en las chilenas? Todo indicaría, en efecto, que la licenciatura, que entre nosotros demora no menos de cinco años -y respecto de la cual quizá aún se crea que constituye la única formación jurídica que recibirá el abogado chileno- se desdobla en otros lugares entre un pregrado bastante más breve y unos necesarios posgrados ulteriores. ¿No habría que pretender por ende para la carrera de Derecho una menor duración y un mayor énfasis en la formación humanística e incluso científica -sea esta contemporánea de estudios jurídicos entendidos como pregrado, sea anterior a aquellos si es que fueran entendidos como posgrado? ¿Hay ya algún síntoma alentador al respecto en el panorama chileno?

Se aprecian unos primerizos y todavía tímidos ánimos reformistas del currículo jurídico nacional. La semestralización se ha impuesto no sin resistencias; pero, a lo que parece, irreversiblemente, además de lo cual existen algunas experiencias de atenuación de nuestro enorme generalismo curricular e, incluso, de introducción -como reemplazo y complemento de las asignaturas dogmáticas- de disciplinas humanísticas y científicas ${ }^{33}$. Es, por ejemplo, el caso del plan de estudios de la universidad privada santiaguina Diego Portales ${ }^{34}$, cuya descripción de la carrera de Derecho reza como sigue: "Derecho en la UDP persigue formar hombres y mujeres capaces de entender todas las dimensiones del fenómeno jurídico y de desempeñarse en los diversos roles o funciones de la profesión legal. En este sentido procura

proyecto se mida en términos de la cantidad de usuarios externos de la investigación o de los indicadores de impacto'. Los investigadores de las disciplinas humanísticas deben insistir en que sus trabajos suponen 'un conjunto de maneras de encontrarnos con el registro de la actividad humana en su mayor riqueza y diversidad' y, por tanto, son valiosos. Si no protestan de este modo, los humanistas de Gran Bretaña dedicarán cada vez más tiempo a 'convertirse en vendedores de puerta en puerta para versiones vulgarizadas de productos cada vez más pensados para el mercado"': NUSSBAUM, M., cit. (n. 30), pp. 172-173.

${ }^{33}$ Hay una preocupante tendencia, por otro lado, en ciertas universidades chilenas, que han venido reduciendo las asignaturas correspondientes a saberes jurídicos como teoría y filosofía del Derecho, o historia del Derecho y Derecho romano, o sociología del Derecho, para no decir nada de la exclusión sumaria de saberes humanistas: Lógica, Filosofía o lenguas modernas (para no decir nada de la desaparición de las lenguas clásicas). Esto acaece incluso en las dos que, por otro lado, dicen ofrecer una visión completa del fenómeno jurídico, que citamos a continuación.

${ }^{34}$ Véase: http://www.udp.cl/descargas/facultades_carreras/Derecho/malla/MallaCurricular_Derecho.pdf. 
un equilibrio entre la enseñanza conceptual (teoría legal y dogmática) y la adquisición de destrezas propias de la profesión legal. Igualmente persigue equilibrar la formación en disciplinas del Derecho público y del privado”.

Esta universidad, además, hace algo que otras están imitando, como es permitir que con un año o semestre adicional a los cinco de licenciatura el estudiante pueda obtener un posgrado de "master". Prosigue la descripción: "el plan curricular permite a nuestros mejores alumnos optar en el último semestre a cursar un magíster en Derecho en algunas de las siguientes áreas: Derecho público y litigación constitucional, Derecho privado patrimonial o Derecho penal y procesal penal. Estos magísteres tienen duración de un año, de dedicación exclusiva, con lo que, agregando un semestre adicional a sus estudios, es posible concluir la carrera con el grado de licenciado y de magíster en un área de especialización profesional"35.

Algo parecido hace la universidad privada Adolfo Ibáñez en Viña del Mar y Santiago de Chile, que aprovecha el quinto año - más la realización posterior de una tesis- para obtener un "master” en Derecho. Además de lo cual puede decirse que el currículo jurídico de esta universidad es aún más ambicioso que el de la anterior ${ }^{36}$, en la medida en que la descripción de la carrera de Derecho permite ver una tendencia a conseguir una suerte de estudios de "college" (con variadas asignaturas humanísticas y científicas de formación general y una obligatoria especialización secundaria o "minor") al interior del propio plan de estudios del futuro abogado: "la formación cultural se logra a través del estudio de las artes liberales -Filosofía, Historia, Arte, Ciencias, Política, Economía, razonamiento matemático. Esta formación otorga a los licenciados en Derecho una comprensión sobre el lugar que corresponde al Derecho en el seno de la cultura occidental y, especialmente, sobre los límites de su disciplina. En su formación propiamente jurídica, nuestros egresados de Derecho se caracterizan por su capacidad para comprender la legislación, chilena y extranjera, en el contexto de las sociedades en que se aplica. En otras palabras, entiende no sólo lo que la ley dispone, sino también las razones (de justicia, económicas, políticas u otras) de por qué lo dispone y el modo en que cada ley forma un verdadero sistema con las demás leyes. Esta aproximación al Derecho permite al licenciado de la UAI interpretar la legislación de modo coherente y consistente con su finalidad. Los licenciados en Derecho de la UAI conocen bien los principios esenciales de todas las áreas del Derecho,

${ }^{35}$ Véase: http://www.udp.cl/facultades_carreras/Derecho /carrera_caracteristicas.asp.

${ }^{36}$ Véase: http://www.uai.cl/images/sitio/facultades_carreras/fac_Derecho /Derecho /malla_curricular.gif. 
de manera que están en condiciones de especializarse profesionalmente en cualquiera de ellas, tanto en el sector público como en el privado" ${ }^{37}$.

Dejando a un lado la retórica del caso, estas más o menos tímidas intervenciones curriculares tienen el valor de desafiar, aun que sea verbalmente, la normatividad del canon histórico de los estudios jurídicos chilenos. Probablemente, además, estas son la única clase de reforma que algunas facultades jurídicas estarán dispuestas a emprender.

Lo que ni siquiera se ha intentado, si no me equivoco, pero que a mi modo de ver debería emprenderse cuanto antes - sea a modo de único cambio practicable por ahora, sea solo como primer paso de una deseable reforma mayor- es 'esencializar' las asignaturas dogmáticas del currículo jurídico chileno. Este segundo paso es más exigente que el anterior, y de él se aprecian ciertos esbozos en las mallas curriculares recién mencionadas. Sin embargo, como entre nosotros aún resulta normal contar con unos planes de estudio rígida y enciclopédicamente organizados, puede pensarse que esta segunda vía de reforma es más difícilmente practicable que la primera. Mas, el asunto bien pudiera cambiar de aspecto en el corto o mediano plazo, y esto tanto por motivos universitarios más generales cuanto por cierto malestar perceptible en las propias facultades jurídicas. Salvo, claro, que lograra tener éxito la defensa a machamartillo del canon tradicional, lo que ocurriría si se emprendiera una apología del mismo, digamos una cruzada por la insustituibilidad de cinco años de cursos obligatorios de Derecho civil -sin la menor opción de contenidos- o, con idéntica obligatoriedad y rigidez, de cuatro años de Derecho procesal, o de dos años de Derecho constitucional y administrativo, o de uno entero para abordar la parte especial del Derecho penal. Es cierto que un cambio por la vía esencializante es algo todavía puramente especulativo. Empero, ya se empieza a concebir al menos la posibilidad de adelgazar el currículo e incluso de acortar los años de estudio. Un romanista como A. Guzmán, así, para quien el abogado es un humanista antes que un tecnócrata (más que, como creo, alguien que sabe manejar una herramienta a la luz de fines morales y políticos, y que de todos modos requiere de una excelente formación humanista), piensa que en la formación universitaria de aquel podría y debería reducirse su currículo específicamente jurídico a todos y solos los aspectos esenciales del área de conocimiento o disciplina ${ }^{38}$, dejando pues para eventuales posgrados posteriores (magíster o doctorado)

\footnotetext{
${ }^{37}$ Véase: http://www.uai.cl/facultades-y-carreras/facultad-de-Derecho /Derecho /descripcion-de-la-carrera.

${ }^{38}$ Como lo sugiere, por lo demás, el artículo 9 inciso $2^{\circ}$ del decreto con fuerza de ley $\mathrm{N}^{\circ} 1$ de 1981: "el grado de licenciado es el que se otorga al alumno de una universidad que ha aprobado un programa de estudios que comprenda todos los aspectos esenciales de un área del conocimiento o de una disciplina determinada”.
} 
cursos como los de Derecho de familia no patrimonial, la parte especial del Derecho penal, el Derecho procesal penal, la parte orgánica del Derecho constitucional, el Derecho internacional público y el internacional privado, el Derecho tributario y el Derecho laboral y de la seguridad social, así como el Derecho de minería, el de aguas y otras más ${ }^{39}$. Por supuesto que este listado de cursos prescindibles puede y a mi manera de ver tendría que ampliarse (¿por qué enseñar casi todos los derechos reales o un enorme número de contratos, en vez de escoger unos pocos derechos o algunos contratos representativos que abran las puertas para el estudio de todos los demás, y así por delante, si bien cuidadosamente y paso a paso?), pero constituye un esbozo que según creo marcha en la dirección correcta.

Ahora bien, si ese segundo paso es en alta medida pura especulación, dar un tercero incluso más drástico sería ya pura 'ficción científica ("science fiction”), y no solo para quien crea en las bondades de la educación jurídica chilena, sino también para quien no crea en ellas pero constate empíricamente su difícil modificabilidad. La revolución copernicana, claro, consistiría en -sit venia verbo - 'norteamericanizar' el modo de organizar curricularmente nuestra enseñanza jurídica (argumento, dicho sea de paso, también válido para todas las carreras esencialmente profesionales). Derecho, entonces, pasaría a ser una carrera de posgrado -que puede y debe enseñarse, aunque este sea un asunto a tratar en otro lugar, con medidas razonables de "case method" y de pedagogía socrática-, y tendría que suponer una rigurosa formación humanística previa. Es algo que, hoy mismo, parece en Chile perfectamente impracticable, casi ilusorio. Sin embargo, quizá también haya algún esbozo en esta línea. Tal como algunas universidades privadas recientes han introducido componentes humanísticos en sus "curricula" y han esencializado adicionalmente los mismos, así también una importante universidad tradicional como la Católica de Chile ya ha implementado - si bien de manera optativa y no como un paso imprescindible- el mecanismo del "college" ${ }^{40}$. Por otra parte, hay intelectuales y universitarios que promueven esta alternativa para Chile, la de estudios humanísticos y científicos que antecedan a enseñanzas francamente profesionales como las de Derecho, Economía, Medicina o Ingeniería ${ }^{41}$. En todo caso, la razón para adoptar críticamente los mejores

${ }^{39}$ Véase: GuZmán, A., cit. (n. 1), pp. 343-349, esp. 344 y 347-349.

${ }^{40}$ Véase http://college.uc.cl/.

${ }^{41}$ Por la vía vulgarizadora de cierta prensa escrita se ha dicho que "el sistema universitario chileno presenta un vivo contraste con el modelo sajón. En nuestro país encasillamos a los jóvenes desde el primer día y los transformamos en mono sabiondos, en personas estrechas, en abogados prematuros, psicólogos deprimidos, periodistas iletrados [...]. Este no es el lugar para discutir todos los detalles de una reforma universitaria de verdad revolucionaria. Pero aquí van algunas sugerencias: la duración del 
aspectos de la enseñanza estadounidense del Derecho (que es la de entregar unos conocimientos y unas destrezas profesionales a quienes ya han recibido con antelación una educación superior sólidamente asentada en humanidades y algunas ciencias) podría en Chile, como veremos, valer a fortiori, dada la mala calidad generalizada de la formación escolar que ya han padecido los estudiantes de Derecho y la consiguiente necesidad que ellos experimentan de unos rigurosos estudios universitarios que los habiliten y preparen para afrontar con un mejor mobiliario intelectual el currículo jurídico - cosa que, hoy por hoy, hacen acotadísima y solo remedialmente algunos programas propedéuticos de universidades chilenas, destinados a algunos alumnos talentosos pero severamente dañados en sus conocimientos y competencias por haberse formado en "escuelas vulnerables" ${ }^{\text {" }}$.

8. Cambios curriculares como los mencionados supondrían, cada uno a su manera, exigencias de envergadura para las facultades jurídicas chilenas y,

primer grado debe acortarse a cuatro años. Los dos primeros deben ser de formación general con cursos requeridos (para todos) de literatura, matemáticas, ciencias, estadísticas, economía, filosofía, ciencias políticas y psicología. Además, todo estudiante debe aprobar un taller de escritura, en el que debe demostrar que puede expresar y defender una idea compleja en no más de 500 palabras. Desde luego, en este modelo los estudiantes tendrían que elegir una concentración. Los dos últimos años los dedicarían a especializarse. Los grados obtenidos serían de licenciados en letras, ciencias, psicología, matemáticas, filosofía, historia, u otras disciplinas. La formación profesional de abogados, dentistas, médicos, veterinarios y otros se obtendrían en programas de posgrado de distinta duración. Además, para graduarse como licenciado, todo estudiante debiera ser efectivamente bilingüe. Esto es, debería aprobar un examen de lenguas al nivel requerido para hacer estudios de posgrado en un país cuya lengua no es el español (por ej., el TOEFL para los EE.UU). Imaginémonos, por un segundo, cómo cambiaría Chile bajo este sistema. Habría miles y miles de jóvenes altamente funcionales y productivos, entusiastas y llenos de ideas, capaces de resolver problemas e iniciar emprendimientos, comprometidos con ideas políticas nuevas y audaces. Estos jóvenes sabrían que su vida de aprendizaje no terminaría al salir de la universidad; al contrario, volverían a ella numerosas veces, para especializarse, adquirir nuevos conocimientos, o, si así lo desean, para cambiar de rumbo": EDWARDS, S., cit. (n. 28), p. R9.

${ }^{42}$ Es por ej. lo que se hace en la Universidad de Santiago (USACH), y cuyo hilo rector es que "los talentos están igualmente distribuidos entre ricos y pobres": Principios y evidencias, Propedéutico de la USACH [disponibles en http://propedeutico.usach.cl/ Principios.html]. Véase un reporte reciente en FigueroA, Lorna - GonZÁlez, Máximo, Programa propedéutico USACH-UNESCO. Nueva esperanza, mejor futuro (octubre de 2011), 8 pp. [disponible en http://propedeutico.usach.cl/Documentos_files/ Propedeutico\%20USACH_OCT.pdf]. Un estudio más detallado al respecto es el de Heras, Helena, Exclusión social en la educación superior chilena: programas y politicas para la inclusión (tesis doctoral, Universidad de Leiden, 2009), 111 pp. [disponible en http://www.propedeutico.cl//publicacion.aspx?id=14]. 
por cierto, para las propias universidades. Llevarlos a cabo constituiría todo un desafío para la dogmática jurídica en Chile, cuyos mejores estándares actuales han aumentado su propia masa crítica, pero que aún no abandona del todo sus tradicionales moldes localistas, como si no se tratara con ella de desarrollar un saber verificable ${ }^{43}$. El asunto se conecta, enseguida, con la metodología de la enseñanza del Derecho prevaleciente en Chile, masivamente basada en la lección magistral -la que, en sus justos límites, es una cosa estupenda- y poco dada a apreciar y practicar metodologías activas o socráticas. Y es que los docentes actuales, aun teniendo mayores años de formación que las generaciones anteriores de profesores, fueron a su vez formados en Chile de maneras pedagógicamente muy frontales y pasivas, lo que sigue recibiendo una suerte de tácita, monumental confirmación por parte de la estructura usual de las salas de clase en las escuelas de Derecho chilenas $^{44}$. Los programas de posgrado, como es obvio, debieren elaborarse al hilo de la reorganización del currículo de pregrado, probablemente incluyendo varias materias que hoy por hoy se enseñan injustificadamente en los años de licenciatura. Semejantes cambios en los planes de estudio, además, plantearían elevadas demandas pedagógicas y organizacionales a las escuelas de Derecho chilenas, las cuales - como otras carreras profesionales- exhiben un pésimo récord en cuanto a los años que realmente supone la titulación académica y profesional ${ }^{45}$.

Hay aquí en juego, como ya hemos vislumbrado, unas cuantas cuestiones, las que atañen al sistema universitario e, incluso, al Colegio de Abogados en Chile. Es difícil pensar que cada facultad de Derecho esté en condiciones

${ }^{43}$ Cf. Bernasconi, Andrés, El carácter cientifico de la dogmática jurídica, en Revista de Derecho. Universidad Austral de Chile, 20 (2007) 1, pp. 9-37, que es crítica de Vergara, Alejandro, Medición de la calidad de las publicaciones jurídicas chilenas, en Revista chilena de Derecho, 30 (2003) 3, pp. 427-432.

${ }^{44}$ Cf. GonzÁLEZ, Felipe, Cultura judicial y enseñanza del Derecho en Chile, en Informes de investigación, 14 (2003), pp. 291-319; y Coloma, Rodrigo, El ocaso del profesor Binns. Un ensayo acerca de la enseñanza del Derecho en Chile, en Ius et Praxis, 11 (2005) 1, pp. 133-172. El asunto, este, daría para mucho. Es al menos digna de considerar en Chile la recomendación que hacía Pérez Lledó para la educación jurídica en España, haciendo de ella una enseñanza sumamente práctica y eo ipso sumamente teórica, y por lo mismo sustentada en tres pilares: uno cognoscitivo-dogmático, otro metodológico-argumentativo y un tercero que habría de incluir la evaluación crítica y la justificación de fines y valores político-morales: Pérez Lledó, J., Teoría, cit. (n. 17), pp. 197-268, esp. 206-261.

${ }^{45}$ En Chile, por ej., el tiempo que toma obtener el primer título universitario es de 6,32 años; en los países de la OCDE es en promedio de 4,32 años. Las horas semanales dedicadas a clases y trabajos académicos es en promedio un $25 \%$ superior en Chile respecto de Europa. Cf. estos y otros datos en La Tercera (22 de abril de 2012), pp. 28-29. 
de acometer estos cambios por sí sola, sin asociarse con otras, sobre todo en lo que respecta a los cambios más ambiciosos indicados más arriba en segundo y tercer lugar. Por eso resulta inevitable pensar en la necesidad de que se constituya y funcione regularmente -de manera análoga a como sucede en Alemania y EE.UU.- una asociación de (ojalá las mejores y más complejas) facultades de Derecho chilenas. También, parecería necesario reforzar el papel ético, y aun académico, del colegio profesional de abogados, volviendo pues a considerar el carácter obligatorio de la colegiatura sin por ello descuidar los deberes estatales para con el interés general que justificaren intromisiones en el ámbito colegial -a veces devaluado por comportamientos impúdicamente corporativos de estas organizaciones intermedias ${ }^{46}$. Por lo demás, el defecto varias veces señalado de la deficiente formación de muchos abogados y jueces chilenos, que aquí he abordado solo desde el punto de vista del plan de estudios que todos ellos han seguido en sus estudios de licenciatura, debería ser encarado tanto con una actuación más intrusiva y opinante de dicho colegio en materias éticas y de la formación universitaria de abogados, cuanto por una asociación de facultades jurídicas que entre otras cosas se proponga reestudiar el actual currículo jurídico. El colegio y las facultades, además, tocando un tema que en estas páginas casi no hemos abordado, deberían considerar la conveniencia de instaurar - quizá en vez del primitivísimo, pedagógicamente hablando, examen de grado “à la chilienne”, y de una práctica profesional como la nuestra tan mal organizada y tan poco exigente desde el punto de vista de las competencias concernidas- otro tipo de prácticas profesionales y de examen obligatorio de Derecho al término de los estudios de grado, y unos también obligatorios programas de actualización, como requisito indispensable para continuar ejerciendo liberalmente la profesión luego de cierto número de años (por ej. aprendiendo, mutatis mutandis, de los programas de formación, perfeccionamiento y habilitación de la academia judicial chilena). Tampoco puede dejarse de lado el enojoso problema del sistema de acreditación de carreras y universidades actualmente vigente en Chile, el que, absurdamente, todavía es voluntario para las escuelas de Derecho, y que tan necesitado está de una auditoría internacional que lo revise y, si fuera necesario, permita replantearlo in integrum. En fin, epor

${ }^{46} \mathrm{Y}$ de los cuales, por mencionar un ejemplo, la carencia de oftalmólogos, sobre todo en la salud pública chilena, permite mostrar cuán gravemente puede torcerse el ejercicio de las capacidades autorregulatorias -de cara a las necesidades nacionales- por parte de un colegio como el médico y una sociedad como la de oftalmología. Véase: Banco Mundial - Gobierno de Chile, Secretaría de Redes Asistenciales, Estudio de brechas de oferta y demanda de médicos especialistas en Chile, en Cuadernos de redes, 31 (2010), pp. 5556 [[disponible en: http://www.minsal.gob.cl/portal/docs/page/minsalcl/g_general/ elementos/estudio_bco_mundial.pdf]. 
qué no pensar en que las buenas facultades de Derecho situadas fuera de Santiago - públicas y privadas, antiguas y recientes, que sumadamente son tantas o más que las capitalinas- den pasos asociativos y vayan asumiendo estas tareas tan pronto como sea posible? Reformular la canónica enseñanza jurídica nacional, reaccionando de paso contra el secular y elefantiásico, injusto e ineficaz "santiaguismo" chileno: esto constituiría un gesto poco habitual, una interesantísima y justificable provocación ${ }^{47}$.

${ }^{47}$ Es ciertamente enorme la tolerancia nacional para con los privilegios exorbitantes de Santiago de Chile. El "santiaguismo", esa difusa ideología en cuya virtud se justifica la centralización de las decisiones, las informaciones, los recursos, y se lleva a cabo el consiguiente desempoderamiento del resto del país, pareciera no admitir límites. Y es que millones de chilenos, que aún son muchos más que los que viven en la metróplis, están ya acostumbrados a encontrarse en canales de la televisión abierta y de alcance nacional con el peculiar estado del tráfico vehicular en tal o cual esquina o calle de Santiago. O con reportes pormenorizados del clima que impera en cierta mañana metropolitana. $\mathrm{O}$ de la actual calidad del aire en la capital chilena. O con el Ministro de Transporte y Telecomunicaciones dedicado casi a tiempo completo a remendar los desaguisados del Transantiago y a planificar nuevas autopistas para absorber el geométrico crecimiento del parque automotriz santiaguino -como si su exclusivo o principal cometido fuera el de administrar en la metrópolis el transporte público y el flujo vehicular. Uno querría que alguna vez se colmase la paciencia del Chile no capitalino, que se difundiera una imparable irritación política con el "santiaguismo" - y una que no lo reproduzca, como ha ocurrido con el reciente levantamiento aisenino, y ocurrió antes con el magallánico. Nada nuevo bajo el sol, en todo caso. Ya en 1935 decía Edwards Bello: "convendría que la 'santiaguinería' viera claro esta vez y comprendiera que el movimiento de repudio por sus intrigas constantes, su burocracia y, en fin, su concepto del patriotismo es bastante serio y efectivo en las provincias [...]. Horror a la 'santiaguinería' hay en todos los puertos donde se trabaja, en los centros mineros del norte y los agrícolas del sur hasta Magallanes [...] Lo que propiciamos es un despertar de los regionalismos, necesarios para la armonía nacional": Edwards Bello, Joaquín, Crónicas reunidas (IV) 19341935 (Santiago. de Chile, Ediciones Universidad Diego Portales, 2012), pp. 317 y 323. El "santiaguismo", por supuesto, tiene feroces consecuencias universitarias. Es pan de cada día -por ej. en Valparaíso, Concepción y La Serena- toparse con ellas. Cuando se instalan en otras regiones, en efecto, las universidades santiaguinas siguen -era que no- el patrón factual e ideológico santiaguista. Invierten exiguamente en plantas, en académicos con jornada parcial o completa. Más bien contratan por horas a académicos de las universidades tradicionales de la región (o de Santiago), e incluso a profesionales que no siempre cuentan con la necesaria experiencia y calificación académicas. Sus plantas son mínimas: ja veces una o dos! La investigación, inexistente casi, no se cuenta entre sus prioridades. Ni siquiera podrían ser buenas universidades puramente docentes, puesto que tampoco invierten en profesores que -sin dedicarse a la investigación- constituyan un equipo estable, científicamente bien formado y pedagógicamente capacitado. Compárese cuán distinta es la planta académica de la misma carrera y en la misma universidad cuando es ofrecida en Santiago y cuando lo es en otras regiones. $\mathrm{Al}$ respecto se ha dicho recientemente algo de lo que convendría tomar nota: "la inexis- 
Todo lo cual termina remitiendo, una vez más, al proceso educativo que ha vivido previamente el estudiante de Derecho en Chile, así como al entero régimen de la educación superior en el que se desenvuelven las facultades jurídicas chilenas. Claro es que en Alemania, España y EE.UU. hay unos sistemas preescolares y escolares que, si alguna crisis están viviendo, nos llevan en todo caso una considerable ventaja tanto desde el punto de vista de su virtualidad integradora y democrática como desde el de sus méritos intelectuales y culturales. Se sabe, por ej., que en los resultados de las pruebas internacionales estandarizadas Chile aparece por detrás de estos tres países ${ }^{48}$. Los estudiantes chilenos están arribando a la educación superior, especialmente a estudiar una licenciatura en Derecho, con severos hándicaps respecto de los estudiantes alemanes, españoles y estadounidenses. ¿Por qué? Esto es algo que solo se puede insinuar muy esquemáticamente. Por una parte, en las últimas décadas es ostensible el aumento que ha experimentado en Chile la cobertura de la educación básica, media y superior y la mejoría generalizada de la infraestructura educativa escolar. La educación preescolar también ha mejorado su cobertura recientemente, aunque esta sea aún insatisfactoria. Sin embargo, son severas y poco contestadas las deficiencias de calidad e integración social que lastran a la educación primaria y secundaria chilena.

tencia de un estatuto público y uniforme de la docencia universitaria a nivel de nuestro sistema de educación superior genera, en efecto, fragilidad en el desempeño de dicha función. Esto nos diferencia de todos los sistemas universitarios de excelencia a nivel mundial; y particularmente del sistema norteamericano, donde el 'tenure system' beneficia a los docentes tanto de universidades estatales como privadas, laicas como confesionales, 'complejas' como 'docentes'. Tal carencia de nuestro sistema es un problema serio para la sociedad toda, puesto que las funciones de crear y difundir conocimiento que la sociedad le asigna a las universidades solo pueden ser realizadas a través de un amplio espacio de libertad de expresión académica [...] ¿Qué elementos debiera contener una reforma al estatuto académico universitario chileno? A mi juicio, ella debiera, en primer lugar, garantizar que en todas las unidades académicas del sistema existan plantas de profesores de jornada completa y dedicación exclusiva, cosa que sorprendentemente no ocurre en parte importante del sistema; debiera establecer como requisito para incorporarse a dichas plantas el contar con formación doctoral; debiera establecer mecanismos de evaluación continua del docente; debiera ofrecer esquemas ascendentes de carrera académica; y debiera ofrecer estructuras de seguridad en el empleo que aseguren a los académicos la libertad necesaria para el desempeño juicioso de su función productiva y docente": MuÑoz, Fernando, Libertad de cátedra I, en El Mercurio (22 de mayo de 2012), p. A2 (carta al director).

${ }^{48}$ Para un resumen de los resultados de PISA 2009 -que mide competencias en lectura, matemáticas y ciencias naturales-y del nivel chileno dentro del conjunto de países sometidos a evaluación, véase: http://www.simce.cl/fileadmin/Documentos_y_archivos_SIMCE/evaluaciones_inter/pisa_2009/Resumen_Resultados_PISA_2009_Chile.pdf. 
El asunto tiene múltiples facetas, cada una de las cuales puede ser entendida como una variable de la crisis escolar. En Chile los estudiantes de primaria y secundaria son parte de un sistema de escuelas finísimamente segregadas de acuerdo con el poder económico de las familias que acuden a ellas ${ }^{49}$. Además, exhiben deficientes resultados en aquellas pruebas estandarizadas $-\mathrm{y}$ esto aun cuando algunos de tales resultados hayan mejorado en los últimos años. De semejante sistema escolar proviene precisamente el estudiante de Derecho chileno. Según se trate de una institución altamente selectiva o no, que las hay de ambas clases en Chile, dicho estudiante habrá ingresado a la universidad con o incluso sin buenos puntajes en otra prueba estandarizada de conocimientos como es la PSU, los cuales no necesariamente dicen relación con su talento académico. No cabe duda de que el sistema de selección universitaria refleja perfectamente esta segregación en tanto en cuanto mide conocimientos y no permite un mejor discernimiento del talento académico, que por definición ha de estar parejamente repartido en toda la sociedad. Por otra parte, hay que hacer notar cuán grave es que tampoco muestren buenas competencias en cálculo y lectoescritura ni los mismos profesores de dichos estudiantes (malos docentes, dicho sea de paso, que hoy día difícilmente pueden ser expulsados del sistema educacional), y que ni siquiera exhiba tales competencias una enorme proporción de técnicos y profesionales universitarios recién titulados. Como grave también es el panorama general de las escuelas de pedagogía chilenas, lo que se relaciona con el sospechoso sistema de acreditación de todas las carreras universitarias en Chile. Carreras por las cuales, como si todo lo anterior no bastara, se cobran unos aranceles altísimos (quizá los más altos del mundo, como se insinuaba antes, si se los compara con el ingreso per capita chileno) que son cubiertos en su mayor parte por las familias ${ }^{50}$. Un panorama nada alentador ${ }^{51}$.

${ }^{49}$ Chile es, a escala mundial, uno de los países que muestra mayor segregación social en sus escuelas (que es justo lo que mide el índice de Duncan); véase: Guinguis, Sebastián, Segregación de las elites en el sistema escolar chileno, Seminario para optar al título de Ingeniero Comercial, mención Economía, Santiago de Chile, Facultad de Economía y Negocios/Universidad de Chile 2008, 38 pp. [disponible en http://www.cybertesis. $\mathrm{cl} /$ tesis/uchile/2008/guinguis_s/sources/guinguis_s.pdf].

${ }^{50}$ Véase el reportaje al respecto de Rioseco, J. P., ¿El precio justo? en AméricaEconomia (número especial de 2011 sobre las Universidades en Chile) [disponible en http://rankings.americaeconomia.com/2011/mejores-universidades-chile/art-preciojusto.php].

${ }^{51}$ Para decirlo con unos cuantos números que retratan de cuerpo entero a la educación chilena: "1) menos del $40 \%$ de los niños que requieren cobertura preescolar la tienen. 2) El 40\% de los egresados de educación básica, media y superior no entiende completamente lo que lee. 3) Más del $40 \%$ de los profesores que están egresando de los pedagógicos no entiende completamente lo que lee ni puede realizar operaciones 
9. En Chile no existe, como en Alemania o EE.UU., una "rechtswissenschaftliche Fachdidaktik" ni una "legal education", vale decir, una investigación asentada respecto del currículo jurídico y los planes de estudio que enmarcan la enseñanza del Derecho. Todo lo que se diga al respecto, pues, carga con esta falta de tradición y tendrá el carácter de una argumentación casi preliminar. Lo cual, bien visto, no debiera impedir esta discusión. Si parece deseable y posible mejorar la formación jurídica básica, y hacerlo acortando la extensión temporal de la enseñanza de la dogmática e integrando en la licenciatura (o imponiendo antes de la misma) un ramillete de saberes básicos -Humanidades en primer término y algunas ciencias-, entonces habrá que afinar los argumentos en favor de ambos objetivos y liberar la reflexión para encarar los obstáculos que pueden levantarse a semejantes transformaciones.

aritméticas sencillas. 4) Los profesores ganan en promedio un 40\% de lo que ganan las 10 profesiones mejor remuneradas. 5) La matrícula de educación pública está cayendo aceleradamente por debajo del $40 \%$. 6) Hay un $40 \%$ de tasa de deserción en la educación superior. 7) Los estudiantes de educación superior pagan aranceles $40 \%$ superiores a lo que debiera costar proveerles una educación. 8) Los tiempos reales de titulación en la educación superior son $40 \%$ superiores a lo originalmente previsto. 9) Bastante menos del $40 \%$ de los estudiantes de educación superior está en carreras técnicas u oficios, cuando todo el mundo nos dice que esta cifra debiera ser del orden de 65\%": Waissbluth, Mario, La regla del 40\%, en La Tercera (11.12.2011) [disponible en http://blog.latercera.com/blog/mwaissbluth/entry/la_regla_del_40]. El mismo autor entrega un buen diagnóstico de la educación chilena, con alcances sobre los recientes movimientos sociales del 2011, la incapacidad de las elites políticas para procesar razonablemente tales demandas y un programa bastante sistematizado de las reformas que parece indispensable acometer, en La educasion en Chile esta vien [sic] (Creative Commons, 2011), 220 pp. También lo ofrece, pero con anterioridad a dichos movimientos, y añadiendo de lege ferenda cómo es que debiera transformarse el sistema escolar chileno -de acuerdo con un régimen de ciudadanía, ya no más de mercado, que propenda a la integración social (impidiendo que el rico transmita su privilegio escolarmente) a través de la máxima protección posible de la potestad de los padres para elegir el establecimiento educacional de sus hijos, lo que debiera llevar a prohibir a estos efectuar cualquiera forma de selección (salvo la aleatoria de un sorteo) y toda exigencia de pago por el servicio que prestan-, ATRIA, Fernando, Mercado y ciudadanía en la educación (Santiago de Chile, Flandes indiano, 2007), 128 pp. Respecto de los defectos de la selección universitaria chilena (PSU) y de la educación superior en Chile (cuya impresionante masificación ha ido de la mano con una no menos imponente desregulación y mercantilización de todo el sistema, lo que explica que hayan entrado en este 'mercado' -obteniendo incluso alguna acreditación- instituciones de dudosísima calidad), véase: Koljatic, Mladen - Silva, Mónica, Algunas reflexiones a siete años de la implementación de la PSU, en Estudios Públicos, 120 (2010), pp. 125-146; también el reportaje de Fossa, Lissette, PSU: académicos acusan que consolida la desigualdad [disponible en http://ciperchile.cl/2011/12/12/psu-academicos-acusan-que-consolida-la-desigualdad/]; y, con una perspectiva más amplia, OCDE/Banco Mundial, Revisión depolíticas nacionales de educación: la politica de educación superior en Chile (2009), 329 pp. 
Remover tales objeciones de maneras intelectualmente honestas y modelar razonablemente aquellas transformaciones mediante diseños institucionales que las hagan posibles requerirá, en Chile como en otras partes, un audaz ejercicio imaginativo: "solo quien excluya a priori la posibilidad de verdaderos cambios reduciría los modelos extranjeros de referencia a aquellos que se parecen bastante al que ya tenemos aquí. Pero si lo que tenemos no nos satisface, deberíamos atrevernos a mirar también cosas nuevas y diferentes, sin rendirnos de antemano ante la supuesta imposibilidad de traducirlas y aplicarlas a nuestro país (imposibilidad que muchas veces se asume de entrada cuando está aún por demostrar, paralizando nuestra capacidad de imaginar auténticas alternativas)" 52 .

No debería perderse de vista que cambios curriculares como los esbozados solo son difíciles, pero en manera alguna imposibles. Después de todo, el Derecho supone prâxis y phrónesis, aspira a la dikaiosýne o es objetivación suya, e incluso se relaciona en cierto sentido con la tékhne, lo que es tanto como decir que el ámbito jurídico se refiere a cosas que pueden ser de otra

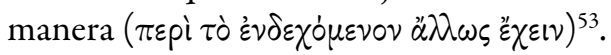

\section{BIBLIOGRAFÍA}

Atienza, Soledad, The Evolution of Legal Education in Spain, en Journal of Legal Education, 61 (2012) 3.

Atria, Fernando, Mercado y ciudadanía en la educación (Santiago de Chile, Flandes Indiano, 2007).

Banco Mundial - Gobierno de Chile, Secretaría de redes asistenciales, Estudio de brechas de oferta y demanda de médicos especialistas en Chile, en Cuadernos de redes, 31 (2010) (disponible en http://www.minsal.gob.cl/portal/docs/page/

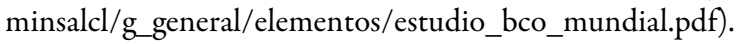

Bernasconi, Andrés, El carácter cientifico de la dogmática jurídica, en Revista de Derecho. Universidad Austral de Chile, 20 (2007) 1.

Breyer, Stephen, "Entrevista a Stephen Breyer, juez de la Corte Suprema de EE.UU." (trad. J. Klein y R. Correa), en Estudios Públicos, 80 (2000).

Brockmann, Judith - Dietrich, Jan-Hendrik - Pilniok, Arne (editores), Exzellente Lehre im juristischen Studium. Auf dem Weg zu einer rechtswissenschaftlichen Fachdidaktik (Berlin, Nomos, 2011).

Brockmann, Judith - Dietrich, Jan-Hendrik - Pilniok, Arne (editores), Methoden des Lernens in der Rechtswissenschaft. Forschungsorientiert, problembasiert und fallbezogen (Berlin, Nomos, 2012).

Coloma, Rodrigo, El ocaso del profesor Binns. Un ensayo acerca de la enseñanza del Derecho en Chile, en Ius et Praxis, 11 (2005) 1.

\footnotetext{
${ }^{52}$ Pérez Lledó, J., Enseñanza, cit. (n. 17), p. 42 n. 2.

${ }^{53}$ Eth. Nic., VI, 4, 1140a21-22.
} 
Eckermann, Johann Peter, Gespräche mit Goethe in den letzten Jahren seines Lebens 1823-1832 (Berlin, Aufbau-Verlag, 1956).

Edwards Bello, Joaquín, Crónicas reunidas (IV) 1934-1935 (Santiago de Chile, Ediciones Universidad Diego Portales, 2012).

EDwards, Sebastián, Nuestra tragedia universitaria, en La Tercera de 7 de enero de 2012).

Figueroa, Lorna - González, Máximo, Programa propedéutico USACH-UNESCO. Nueva esperanza, mejor futuro (octubre de 2011), 8 pp. (disponible en http://propedeutico.usach.cl/Documentos_files/Propedeutico\%20USACH_OCT.pdf).

Fossa, Lissette, PSU: académicos acusan que consolida la desigualdad (12 de diciembre de 2011) (disponible en http://ciperchile.cl/2011/12/12/psu-academicos-acusanque-consolida-la-desigualdad/).

González, Felipe, Cultura judicial y enseñanza del Derecho en Chile, en Informes de investigación, 14 (2003).

Gordon, Robert, La educación juridica en Estados Unidos: origenes y desarrollo, en Temas de la democracia, 7 (2002) 2.

Griebel, Jörn - Gröblinghoff, Florian (editores), Von der juristischen Lehre. Erfahrungen und Denkanstöße (Berlion, Nomos, 2012).

Guinguis, Sebastián, Segregación de las elites en el sistema escolar chileno (seminario para optar al título de Ingeniero Comercial, mención Economía, Santiago de Chile, Facultad de Economía y Negocios, Universidad de Chile 2008) [disponible en http:// www.cybertesis.cl/tesis/uchile/2008/guinguis_s/sources/guinguis_s.pdf].

Guzmán, Alejandro, La enseñanza del Derecho. Historia y perspectivas, en Anales del Instituto de Chile: La educación superior en Chile, 25 (2005-2006) 2.

Heras, Helena, Exclusión social en la educación superior chilena: programas y politicas para la inclusión (tesis doctoral, Universidad de Leiden, 2009) [disponible en http:// www.propedeutico.cl//publicacion.aspx?id=14].

Koljatic, Mladen - Silva, Mónica, Algunas reflexiones a siete años de la implementación de la PSU, en Estudios Públicos, 120 (2010).

LeTElier, Juan Carlos - Mpodozis, Jorge, El sistema es un escándalo y hay que pararlo, en Números, calidad, equidady diseño en el sistema universitario chileno (Dirección de Innovación y Transferencia Tecnológica. Facultad de Ciencias. Universidad de Chile, 2011) [disponible en http://www.vamosviendo.cl/textos/universidad.pdf].

Llabrés, Antoni, Els estudis de dret en Alemanya, en García AÑón, José (editor), Los estudios de Derecho en Europa: Alemania, Francia, Italia, Reino Unido e Irlanda (Valencia, Servei de Publicacions de la Universitat de València, 2008).

Llovet, Jordi, Adiós a la universidad. El eclipse de las Humanidades (trad. A. Fuentes, Barcelona, Galaxia Gutenberg - Círculo de Lectores, 2011).

Merico-Stephens, Ana María, Notas sobre la historia de la enseñanza del Derecho en los Estados Unidos, en Cuadernos del Instituto Antonio de Nebrija, 7 (2004).

MuÑoz, Fernando, Libertad de cátedra I (carta al director), en El Mercurio de 22 de mayo de 2012).

Nussbaum, Martha, Sin fines de lucro. Por quéla democracia necesita de las humanidades (trad. M. V. Rodil, Buenos Aires, Katz, 2010).

OCDE - BANCo Mundial, Revisión de politicas nacionales de educación: la politica de educación superior en Chile (2009).

Ortega y Gasset, José, Misión de la Universidad, en Obras completas 1926-1931 (Madrid, Taurus, 2005), IV. 
PALAo, Guillermo, Los estudios de Derecho en los estados europeos de habla inglesa: Reino Unido e Irlanda, en GARCía AÑón, José (editor), Los estudios de Derecho en Europa: Alemania, Francia, Italia, Reino Unido e Irlanda (Valencia, Servei de Publicacions de la Universitat de València, 2008).

Peñuelas, Lluís, La docencia y el aprendizaje del Derecho en España. Una perspectiva de Derecho comparado (3a edición, Barcelona, M. Pons, 2009).

Pérez Lledó, Juan, La enseñanza del Derecho en los Estados Unidos, en Doxa, 12 (1992).

Pérez Lledó, Juan, Teoría y práctica de la enseñanza del Derecho, en Anuario de la Facultad de Derecho de la Universidad Autónoma de Madrid, 6 (2002).

Rioseco, J. P., ¿El precio justo? en AméricaEconomía (número especial de 2011 sobre las Universidades en Chile) [disponible en http://rankings.americaeconomia. com/2011/mejores-universidades-chile/art-precio-justo.php].

Sheppard, Steve (editor), The History of Legal Education in the United States: Commentaries and Primary Sources (The Lawbook Exchange Ltd. 2007), I-II.

Toller, Fernando, Orígenes históricos de la educación jurídica con el método del caso, en Tenorio, Guillermo (coordinador), Humanismo jurídico. Ensayos escogidos (México, Porrúa - Universidad Panamericana, 2006).

UsaCh, Principios y evidencias, Propedéutico de la USACH [disponible en http:// propedeutico.usach.cl/Principios.html].

Vergara, Alejandro, Medición de la calidad de las publicaciones jurídicas chilenas, en Revista chilena de Derecho, 30 (2003) 3.

Waissbluth, Mario, La regla del 40\%, en La Tercera de 11 de diciembre de 2011) [disponible en http://blog.latercera.com/blog/mwaissbluth/entry/la_regla_del_40].

Waissbluth, Mario, La educasion en Chile esta vien [sic] (Creative Commons, 2011). 

